\title{
TECHNIQUES FOR REVEALING 3D HIDDEN ARCHEOLOGICAL FEATURES: MORPHOLOGICAL RESIDUAL MODELS AS VIRTUAL-POLYNOMIAL TEXTURE MAPS
}

\author{
Hugo Pires ${ }^{\text {a }}$, José Martínez Rubio ${ }^{\text {b }}$, Artzai Elorza Arana ${ }^{\mathrm{c}}$ \\ ${ }^{\mathrm{a}}$ CICGE - Research Centre for Geo-Space Sciences, University of Porto (miqhapaqnan@gmail.com) \\ ${ }^{\mathrm{b}}$ LFA-DAVAP, University of Valladolid (jmrubio@ega.uva.es) \\ ${ }^{\mathrm{c}}$ University of Salamanca (artzai.elorza@gmail.com)
}

Commission V, WG V/4

KEY WORDS: Morphological Residual Model, Archaeology, Engravings, 3D, Polynomial Texture Mapping

\begin{abstract}
:
The recent developments in 3D scanning technologies are not been accompanied by visualization interfaces. We are still using the same types of visual codes as when maps and drawings were made by hand. The available information in 3D scanning data sets is not being fully exploited by current visualization techniques.

In this paper we present recent developments regarding the use of 3D scanning data sets for revealing invisible information from archaeological sites. These sites are affected by a common problem, decay processes, such as erosion, that never ceases its action and endangers the persistence of last vestiges of some peoples and cultures.

Rock art engravings, or epigraphical inscriptions, are among the most affected by these processes because they are, due to their one nature, carved at the surface of rocks often exposed to climatic agents. The study and interpretation of these motifs and texts is strongly conditioned by the degree of conservation of the imprints left by our ancestors. Every single detail in the remaining carvings can make a huge difference in the conclusions taken by specialists.

We have selected two case-studies severely affected by erosion to present the results of the on-going work dedicated to explore in new ways the information contained in 3D scanning data sets.

A new method for depicting subtle morphological features in the surface of objects or sites has been developed. It allows to contrast human patterns still present at the surface but invisible to naked eye or by any other archaeological inspection technique. It was called Morphological Residual Model (MRM) because of its ability to contrast the shallowest morphological details, to which we refer as residuals, contained in the wider forms of the backdrop.

Afterwards, we have simulated the process of building Polynomial Texture Maps - a widespread technique that as been contributing to archaeological studies for some years - in a $3 \mathrm{D}$ virtual environment using the results of MRM calculations. By this, we wish to benefit from the rendering capabilities of RTI-viewer and from its intuitive graphic interface. At the same time, virtual PTM is a way of applying this to areas barred to conventional PTM, like in the case presented of an entire roman city occupying a plateau of several sq. km.

The results of this research project are presented and discussed using the two case-studies aforementioned, a Latin inscription from a Roman sanctuary in the north of Portugal and a engraved panel with zoomorphic motifs from a rock art site in the north border of Portugal.
\end{abstract}

\section{INTRODUCTION}

Erosion is one of the most important factors affecting the conservation of archaeological sites and objects. Every pronounced feature in a rock surface that we know tends to disappear sooner or later affected by this process. Over time, shapes carved by humans become progressively fainted, ultimately leading to its complete loss (Siegesmund et al., 2002) (Pipkin et al. 2014). An increasing public awareness of the damage affecting archaeological sites as lead to major conservation campaigns and scientific studies carried out all over the world that address the origins and consequences of climatic changes in cultural heritage $(\mathrm{CH})$. As a consequence, sites directly exposed to climatic agents are among the most

\footnotetext{
* Corresponding author.
}

affected but, to a certain degree, every $\mathrm{CH}$ tangible asset is endangered.

Our attention is focused in the specificity of open-air sites with engravings or any form of human carving. These sites, often object of study for epigraphy and rock art specialists, are extremely exposed to damage by erosion from natural or human action. One of the principal consequences affecting this types of archaeological evidences is the progressive loss of material from the rock superficial level, seriously affecting theirs state of conservation (Gaddi et al., 2015)

Every incision technique used in the past to carve forms on the stone involved applying a certain amount of energy by impact or friction so to remove material from the surface. The energy used to produce the grooves is the cause for changes to the micro-structural level turning a carving into a weak point in the surface matrix. Cavities are more prone to the accumulation of 
water and debris, fostering the proliferation of biotic colonies and the action of weathering agents. In addition, the edges of grooves are more exposed to erosion and are more fragile than a regular surface. Another important factor in the severity of erosion effects in archaeological sites is the rock origin and composition. The superficial desegregation tends to provoke more serious damages to engravings in rocks with coarsegrained textures than those with smaller crystal structure. Contour definition and groove sharpness are eroded faster in granites or sandstones than in limestones or marbles.

For many years in archaeological research, rock carvings and engravings were inspected using techniques that are nowadays considered unacceptable because of their harmfulness to the rock surface. Those that require mechanical actions in the outcrops, like pressure or friction, or involve chemical interactions with external substances may compromised their conservation are the most detrimental for conservation purposes. Techniques such as scraping with charcoal on paper or pouring melt substances such as plaster or latex to obtain a negative mould have been almost completely abandoned from archaeological field practices.

The pursue for more effective ways of recording, detecting and inspecting ancient engravings is a current commitment for a large number of researchers in the archaeological broad scientific community. 3D Scanning technology as been one of the major contributors for improving recording methods in archaeology. We have now arrived to the time when a simple digital photo-camera with appropriate processing software can be used to $3 \mathrm{D}$ scan objects or sites without damaging them, achieving incredible resolutions and at a incredible low cost.

Although a lot of effort is being putted in recording $3 \mathrm{D}$ data, we continue to mimic the way we visualized and depicted it before the major event of 3D scanning. As an example, the same graphic codes once used for depicting altitude in flat maps, such as equidistant contours, are still being done, but now from 3D scan data sets, representing a significant cutback on the amount of information available. Building surveys using 3D scanning technology are, in most cases, fate to end in vector drawings like plans, sections or elevations calculated from 3D point clouds. Again, a huge part of the information is lost in translation. Our contribution to this shift concerns the way we use these records after acquisition and processing steps. We believe that, to fully explore the benefits of the increasingly available $3 \mathrm{D}$ scanning data, new ways of seeing and interacting must be persecute.

To test our ideas in a challenging environment, we have chosen to focus our efforts in the very delicate remains of ancient engraved archaeological sites, carved in granite outcrops severely damaged by erosion agents.

\section{CURRENT TECHNIQUES FOR INSPECTING AND RECORDING ENGRAVED ARCHAEOLOGICAL SITES}

The documentation and visualization techniques have evolved along history, following the changes in society attitude towards $\mathrm{CH}$. A vast number of methodologies have been used to record epigraphy and rock art. In recent years, we have witnessed a clear evolution regarding the techniques for visual inspection of engravings. They have matured with a progressive awareness of society towards Cultural Heritage conservation, changing its character from invasive to non-invasive; from non-digital technique to digital technique; and merely documentary to combination of documentary and diffusive.

These can be classified into two groups according to the amount of recorded dimensions:

\section{D methods:}

- Sketching or tracing on translucent or transparent media such as plastic film and vellum paper superimposed to engraved surface.

- Frotagge, a rubbing technique.

- Tracing photographs.

- Polynomial Texture Maps ${ }^{1}$

3D methods:

- Moulding

- Direct discrete tracing. Consist on collection of $3 \mathrm{~d}$ line strings connecting points measured by touch probes (contact) or total station (non contact)

- Photogrammetric discrete methods. Understood as those that require a human being to perform the digitization of features engraved in the rock by means of a plotter.

- Scanning. Digitizing surfaces by means of laser or structured light scanners that allow a dense collection of points or digital meshes or alternatively by means of recent image-based techniques that use pairs or sets of overlapping photos to produce dense point cloud representation of surfaces.

The first two techniques have been the standard procedure prior to digital era. They are seen today as less scientific but despite being objectionable due to their invasive character, they have honourably served along too many years as a recording technique have been for years the only existing technical methods of graphic documentation, and they owe most of our knowledge of rock art. The so-called frottagge aims to get the imprint of the relief by rubbing a paper placed on the stone with a material that stains such as charcoal, graphite or pastel. This often helps to transfer to the paper some already worn motifs.

Another technique, called bi-chromatic, was thoroughly used by many archaeologists during some decades. Today it is unanimously considered as highly invasive and susceptible of causing harm. It's also intended to enhance the readability. Consists on applying white powder or ink to the engraved stone and, after that, rubbing a dark substance directly on the rock to blacken the areas that are not carved. In this way, the contrast is pushed up and the carvings are turned into a sort of black and white filter. Although cost effective, its aggressiveness isn't acceptable under current standards in $\mathrm{CH}$ conservation. The same considerations apply to qualify moulding technique today as an objectionable practice.

For the purposes of this study we have only consider the most frequently used techniques: raking light photography, 3D scanning and PTM. Two different case-studies were selected to assess the suitability of the different methods: a Latin inscription from the Roman sanctuary of Panóias and a panel with engravings from the rock art site of Monte Faro, both in the North of Portugal. Archaeological studies are being

1 For the purposes of this paper, Polynomial Texture Maps and Reflectance Transformation Imaging are considered as a unique solution and are both referred to as PTM. 
conducted in these sites (Correia Santos et al., 2014), (Pires et al., 2015a).

\subsection{Raking light technique}

Now that we have outlined the different tools and technologies for capture 3D data, lets talk about how to face the problems of reading and interpretation the motifs when they are faded by weathering or other forms of decay. The cinema has shown us many times the image of an archaeologist bringing a torch or a candle and moving the light source to help reading of engraved findings. This gesture of seeking for the best point for a raking light to enhance carved forms to our eyes is certainly the oldest method of inspection, and its usage will surely be contemporary with the creation of the carvings itself. It is still used today in the very same fashion and remains unsurpassed as the primary tool for on-site analysis. Despite of being an active inspection method, it is such a common one that most consider it as unimportant as the simple passive direct inspection.
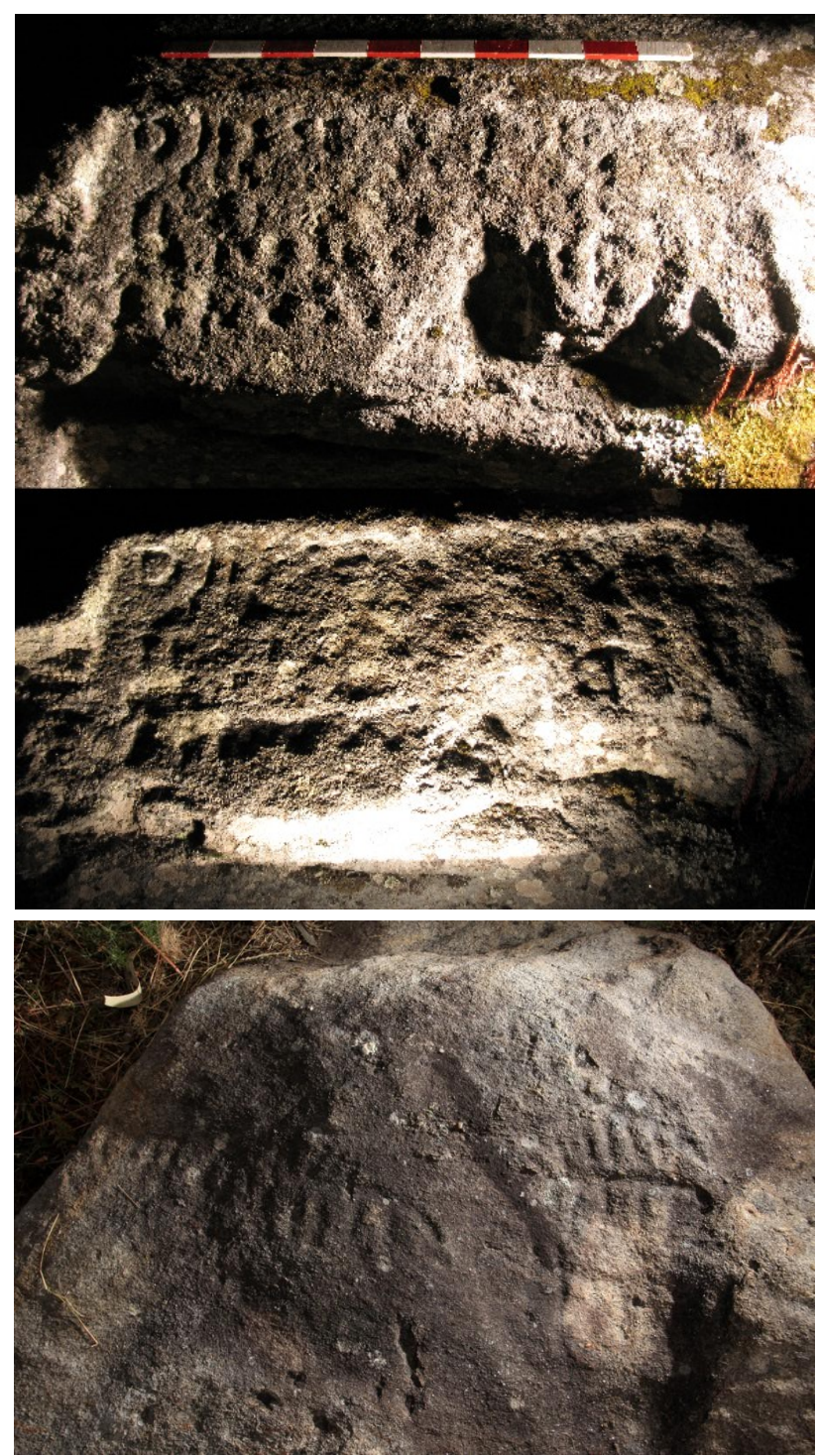

Figure 1: Top: Raking light photographs of a Latin inscription from the sanctuary of Panóias (Portugal) with two different light directions. Bottom: Raking light photograph from Rock 4 at the rock art site of Monte Faro (Portugal). Photographic credits M. J. Correia Santos (top) and L. Bacelar Alves/M. Reis (bottom).

The recording of this information is usually done in two different ways: photographing the surface illuminated by directional spotlights from different tangential positions and tracing by hand the apparent contours of engravings and main geological features using a transparent film overlaid to the stone surface. Both techniques are often used in conjunction and tracing is done directly on photos taken under raking lighting. Although photographs are far more objective than tracing, they only allow for fragmented records, each corresponding to the unique point of view and shading condition captured in the photography. Usually, several photographs with different light directions are needed to record the entire scene.

One of the major drawbacks this method presents is a fragmented perception of the assemblages because each trace of engraving is better perceived when the light comes from a perpendicular direction to the groove attitude (Figure 1, top). Furthermore, irregular outcrops are very difficult to lighten homogeneously because of shadow effects from spotlights (Figure 1, bottom). Usually, multiple light positions must be used to document the entire scene, therefore a suitable method to combine the feature lines revealed at each lighting condition must be implemented.

Last but not least, this technique is very susceptible to the intrinsic colour texture of rock surfaces that, along with the patina of biotic or chemical origin, envelops and masks the carvings features, preventing archaeologists of having a clear perception of all the existing remains.

\subsection{D Scanning}

Digital techniques are changing the way archaeological records are made. Several new solutions have come to light in these last decades. One of the major trends is 3D scanning (Barber et al., 2011), that is increasingly being used in archaeology to produce full records of sites and objects shape, dimensions and position. The improvements achieved by non-contact 3D scanning techniques in archaeological recording are an huge step forward when compared to non-digital techniques. Apart from allowing to record surfaces in three dimensions with astonishing resolution and without any damage to the integrity of the physical materials, they decrease the time and cost needed to accomplish recording tasks in archaeological sites.

These non-invasive techniques allow for detailed and accurate representations of surfaces that can be used to produce conventional drawings (e.g. plans, elevations, sections) or other non-conventional types of visualization like videos or virtual reality. Applied to our case-studies, this technique allowed to calculate dense point clouds with sub-millimetre resolution from rock surfaces previously known for having archaeological evidences. Due to damage inflicted by erosion, both presented a conservation state that prevented any clear reading of the motifs. The interpretation of these ancient testimonies as been therefore conditioned.

Several important advances are achieved by 3D scanning. One is the possibility to separate the colour texture from the $3 \mathrm{D}$ model, thus revealing the shape underneath in a homogeneous tonality making motifs easier to detect (Figure2). In these virtual environments, as much as in real situations, light can be 
directed from any point of view, and so, raking light can also be simulated. Despite these clear benefits to recording engravings, it still presents the same drawbacks as raking light.

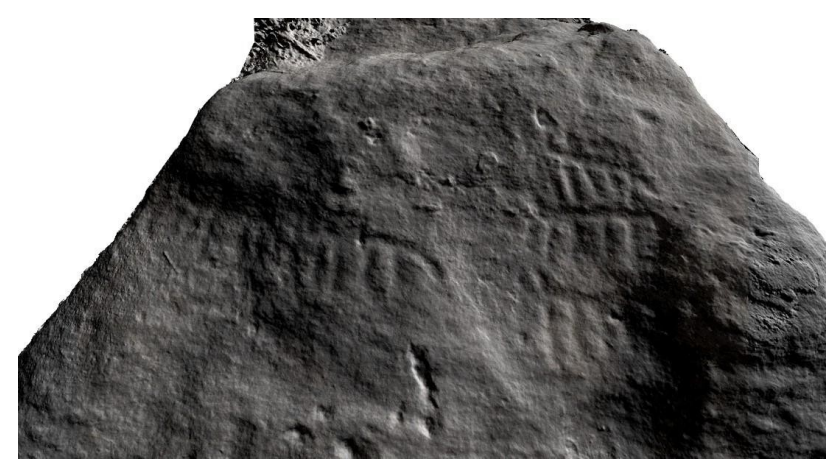

Figure 2: Snapshot from the 3D scan model of the same panel as in Figure 1, with the simulation of raking light.

\subsection{Polynomial Texture Mapping}

Another technique that is achieving an important place in archaeological recording is the Polynomial Texture Mapping (PTM) (Malzbender et al., 2011). This technique uses sets of photographs of a scene, all taken from the same point of view, differing only in the light incidence angle used. The results are displayed in a 2D interface, called RTI viewer, allowing the user to interact with the scene by virtually dragging a directional light source and rendering the light changes in real time.

PTM has a promising future as a recording technique for cultural heritage as it is being continuously improved by different researchers in many ways. An innovative approach to PTM visualization is to replicate the process of image capture in a virtual environment. Mostly any $3 \mathrm{~d}$ modeling programs such as Autodesk 3DS or Blender allow to emulate the behavior of a real camera and can capture snapshots of the $3 \mathrm{~d}$ scenes as if they were taken in real scenarios (Earl et al., 2010a). The simulation capabilities include also the placement of virtual light sources whose interaction with geometry and physical properties assigned to the virtual objects can faithfully simulate real world scenes. These two features together allow us to emulate the work-flow of the PTM technique.

This process is what is known as Virtual PTM (V-PTM) and presents some interesting advantages. There is no limitation to the size of the object or scene because the construction of a physical assemblage of camera and lights is not required in virtual worlds. Also, the process of lighting is completely under control in a virtual environment, so there are no worries about intruding light sources that could affect the estimation of light source position. The virtual camera is ruled by a mathematical model thus free of chromatic or geometric lens aberrations. Similarly, the virtual snapshot is free of noise and artifacts and is always perfectly sharp. In one word, the simulation is capable of gathering all PTM benefits without any limitations; being the model fidelity the only factor that can negatively affect the rendition of its virtual variant.

Among other major benefits, like the simplification of the capturing process, by using this approach every $3 \mathrm{D}$ model can be converted in a multitude of PTM files, one for each possible point of view. Furthermore, V-PTM widens the possibilities of application of PTM to fields where it was not possible before. An example is the 3D model of the Roman city of Clunia, in Spain, that occupies several square kilometers (Figure 3). The 3D data was calculated from photographs taken with digital cameras attached to unmanned aerial vehicles.

V-PTM allows for the effortlessly evaluation of many different light sources distribution by the automation of the spot-light placement and its resulting rendered scene capture. We can even test the ability of RTI builder software to estimate accurately the positions of the light by adding a black sphere to the scene in the way it is used in non-virtual cases. This approach can lead to conclusions about the optimal distribution of light sources, or the choice of the simulated optical parameters and settings to create rendered scenes that introduce less uncertainty.

Tests have enabled us to build an optimized framework to process virtual photos in RTI-builder, obviating the step of estimating the position of the spotlight since that can be stated rather than estimated. We were able to partially automate this process by programming an application that requires the user to enter the number of spotlights, the number of heights where the lights will be distributed, and the maximum dimension of the object. The program returns a complete script that commands the creation and toggling of virtual lights in $3 \mathrm{ds}$ Max and executes the corresponding iterated rendering of the scene under the changing light conditions (Figure 4).

Beyond being another iteration of the use of V-PTM technique in which our contribution as been the optimization and automation of the process, the most interesting achievement is the inclusion of a synthetic colour map (the colour coded results of the MRM) as if it was the colours in a photograph.

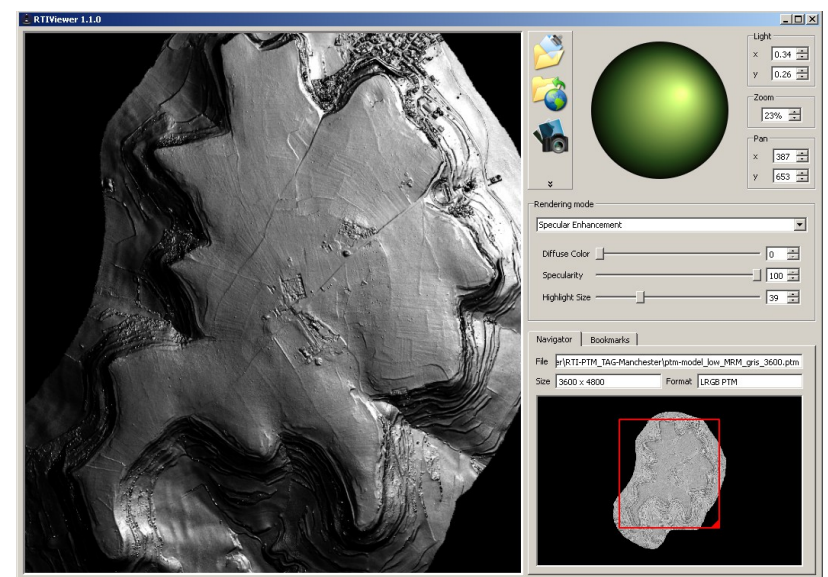

Figure 3: Results of the V-PTM applied to large sized models of earth surface: the Roman archaeological site of Clunia, Spain, (around 4 sq. Km.).

As in the previous techniques, also PTM is light-dependant has an inspection tool. The considerations presented for 3D scanning are also valid to PTM results. When compared to $3 \mathrm{D}$ models it lacks of three-dimensionality, but, in a certain way, this same reason can be taken as an advantage. The complexity of operating a 3D data viewer is far more high than in RTIviewer. 


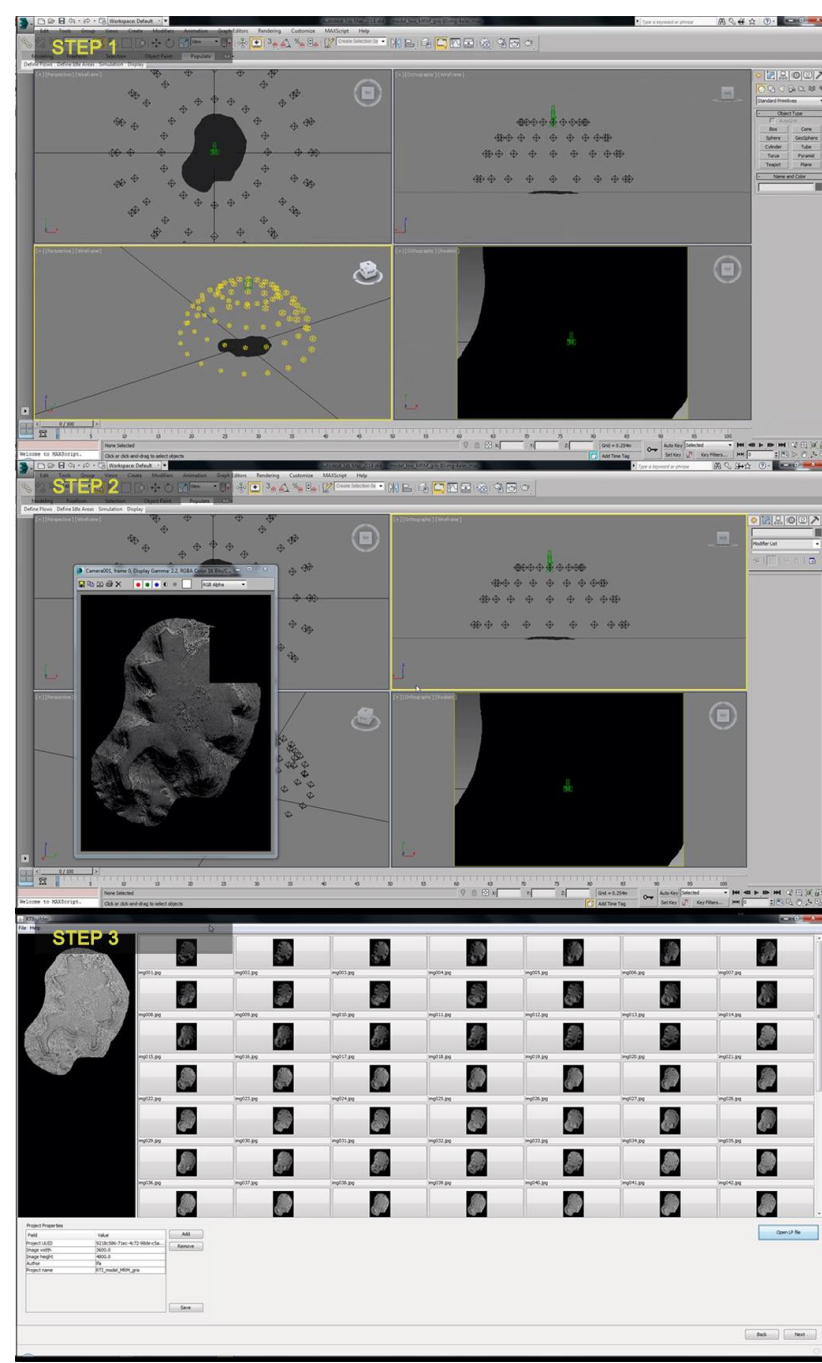

Figure 4: V-PTM processing pipeline (from top): Virtual light dome; image capture using rendering filters; assemblage of PTM using RTI Builder to process the virtual photographs (video available at: http://youtu.be/-QjSMeumSjE ).

\section{NEW APPROACH FOR ENHANCED 3D MODEL VISUALIZATION: MORPHOLOGICAL RESIDUAL MODELS AS V-PTM}

All the aforementioned techniques, digital and non-digital, present the same type of constraints to the visual inspection of fainted motifs carved in stones. Our proposal points in another direction, aiming to contribute to overcome visualization problems related to this conservation conditions, common to many $\mathrm{CH}$ sites around the world. It consists in using a combination of two different techniques to achieve a new hybrid output, a V-PTM for inspecting MRM, benefiting from the good features of both worlds. Although apparently pointing in opposite directions, this two techniques can be integrated because of the V-PTM approach.

MRM uses $3 \mathrm{~d}$ mesh models out of any shape reconstruction technology to calculate contrasted depictions of micro-relief features in 3D models contributing significantly to increase the amount of information available for archaeological researchers. When applied to 3D models of eroded sites or objects it reveals morphological details that are not easily perceived by the human vision, by depicting small shape variation in any $3 \mathrm{D}$ surface as a colour code attribute for each in the $3 \mathrm{D}$ model. The processing is based in a trend removal technique that allow to calculate residual morphology of engravings. The residual values are coded in a colour scale and assigned to the 3D model as vertex colour attributes. The results are $3 \mathrm{D}$ models where small morphological features appear as consistent colours, independent of light orientation (Pires et al., 2015).

This new tool can be considered as an advanced visualization technique, which uses 3D models derived from digital scanning systems. It appears therefore that it is not appropriate to situate it among recording technologies but in another separate category for post-processing 3D models. Perhaps it is so, but if we examine all the listed techniques, we note that scanning techniques, despite being the richest in potential content, are blind in the sense that the recorded is done in an undifferentiated way. The absence of a purpose gives equal importance to areas carved as to those that aren't. In this sense we can think of MRM as a more "intelligent" approach because it contributes to give meaning to underlying the shape captured by scanning. Therefore, more than being just a $3 \mathrm{~d}$ data treatment, we consider that MRM together with scanning configures a capture technique highly adequate for engravings or any other subtle morphological evidence of human action.

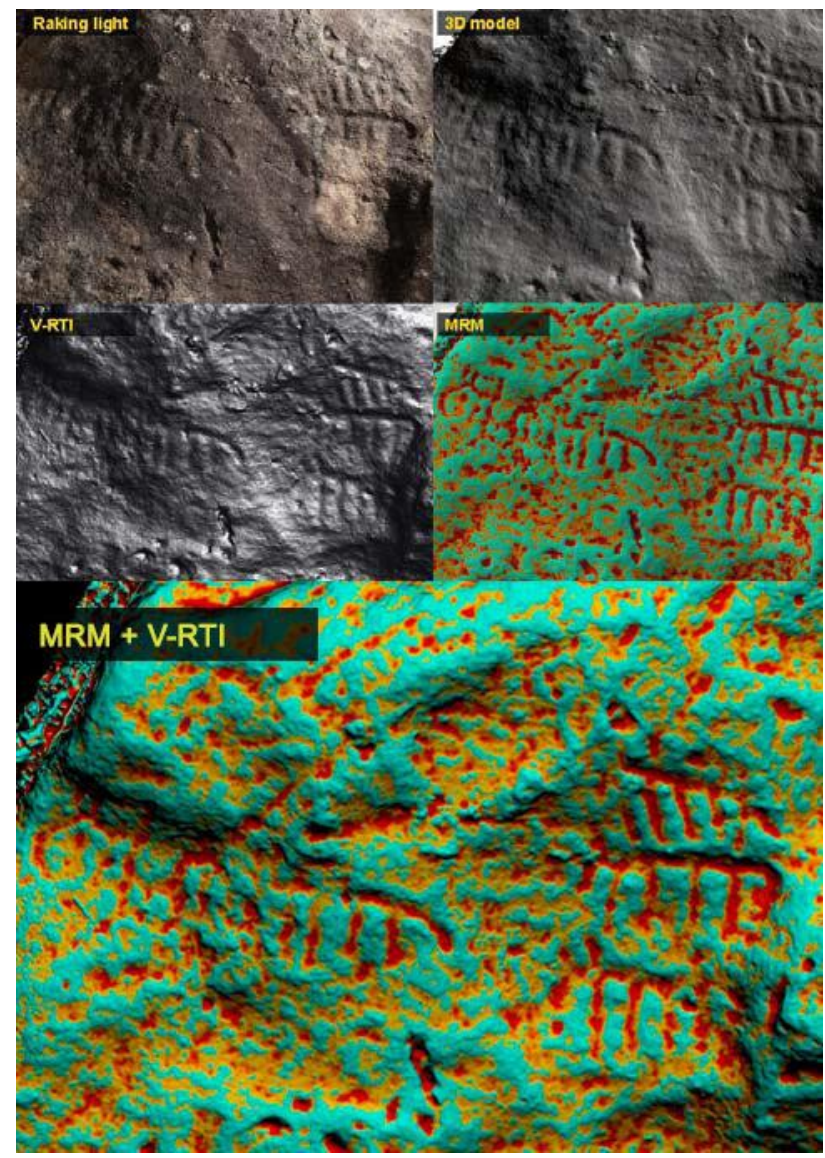

Figure 5: Results of the entire set of techniques discussed in the same engraved panel (from top, left): Raking light photography, 3D scanning, V-PTM, MRM and, at the bottom, MRM in RTIviewer). 
Once that the surface texture of the 3D model as been remapped with the MRM results, we make use of the V-PTM technique to facilitate the virtually inspection of the engravings, combining the advantages of the new colour coded shape depiction with the effectiveness of the RTI viewer interface. The bidimensional intrinsic character of PTM is taken as a way of simplifying the inspection tasks: interacting with $3 \mathrm{~d}$ models in virtual environments can be an annoying and time consuming operation, specially when dealing with models with large quantity of data, like point cloud based meshes, so maybe a $2 \mathrm{D}$ solution can help to improve the receptivity of archaeologists.

The wide range of tests carried out so far in different archaeological contexts confirm that the perception of subtle morphological features is significantly enhanced when using MRM (Correia Santos et al., 2014, Pires et al., 2015a). The traces still present in the stone's surface become depicted in a way that reduces the ambiguity that light-based techniques present.

\section{RESULTS}

As mentioned above, the proposed methodology was thoroughly applied in two different archaeological sites, an Atlantic rock-art assemblage with a large number of engravings in granite outcrops and a Roman sanctuary where four inscriptions in Latin and Greek still testified the ancient cults. Both are considered to be of very difficult reading due to erosion factors and, before the use of MRM, were not fully "read" by archaeologists. In the case of Panóias, studied for some decades, this lead to controversial interpretations. The contribution of the clear depictions for the archaeological knowledge of these important inscriptions was recently presented to the scientific community (Correia Santos et al., 2014, Pires et al, 2014) and made available online ${ }^{2}$.

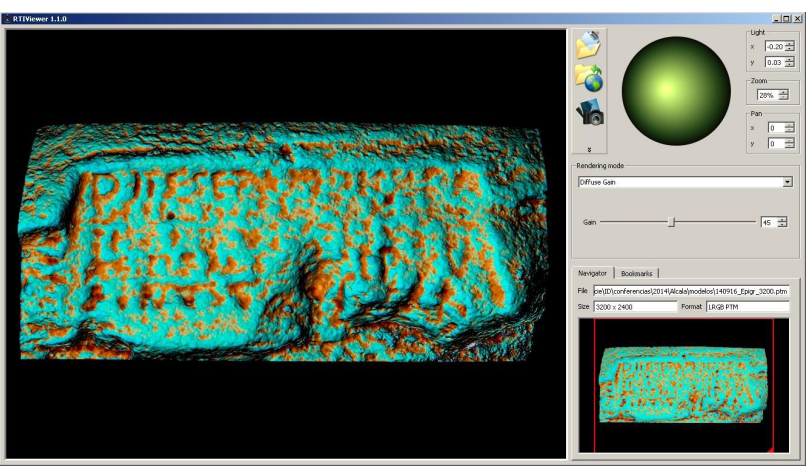

Figure 6: The final result of the proposed methodology: a V-

PTM built from a MRM colour-coded 3D model of an inscription from Panóias sanctuary.

Although light is still needed to observe virtual 3D models with MRM codification, the perception of small scale relief is considerably enhanced by the presence of colour as a local deepness factor.

Furthermore, MRM outputs such as digital orthophotos, videos or even PTM, can be considered as scientific depictions per se. Indeed, MRM can be considerer a new category of information, as much as non-visible radiation photography is for

2 A digital version can be found at: http://www.eagle-network.eu/eaglefirst-international-conference-proceedings-now-online/ conventional visible spectrum images. This new category of depictions can in fact reveal non-visible shape information.

From a certain point of view, the use of PTM as an output of MRM, can be considered counter-productive as it corresponds to a significant reduction of the information available in 3D model. Yet, considering the excellent rendering performance of the RTI-viewer and the easiness with which light interaction simulates a $3 \mathrm{D}$ environment, it is out opinion that RTI-viewer is an excellent vehicle for delivering information to who needs it.

\section{CONCLUSIONS}

When dealing with highly eroded surfaces light-dependant techniques will unlikely be able to deliver clear and unambiguous depictions of subtle morphological details and, therefore, new approaches must be pursued. For many $\mathrm{CH}$ cases, the time is getting over for apprehending the meanings of ancient carved rock art. Climate changes issues are jeopardizing archaeological sites, worsening conservation problems and so we must urgently respond to the need to retain the most meaningful and comprehensive snapshot of our past.

Having in mind that nowadays a large number of $\mathrm{CH} 3 \mathrm{D}$ records are being accomplished by image-based techniques (like the examples presented in this work), it is rather ironic to realize while looking back, the astonishing amount of images captured for each model processed, from the initial set of photographs taken with digital camera to the virtual processing of PTM. Inspired by this work, we say that digital photographs are an extremely rich source of knowledge, capturing information far beyond what we can imagined each time the shutter release button is pressed. The inspection of MRM using the RTI-viewer interface, is an effective, yet simple, way of delivering valuable and accessible data to archaeologists.

The RTI-viewer is as a promising tool for inspection of 3D models-derived data. It would be very interesting to assist in a near future to the emergence of a digital tracing tool working within RTI-viewer that could contain image orientation parameters for each PTM view, allowing for direct correspondence between the source 3D model and PTM. Multiview would also be a valuable attribute for profiting from the richness of $3 \mathrm{D}$ scanning data.

Other fields of archaeological studies, and other sciences as well, can be potential beneficiaries from the methodological and technological improvements we have presented here. For this purpose, several tests are being carried out at multiple scales, ranging from geomorphological scale of landscape to small artefacts in underwater environments. We hope our work can contribute to foster new developments in 3D data processing and visualization. 


\section{REFERENCES}

Barber, D. and Mills J., 2011. 3D Laser Scanning for Heritage (second edition). Advice and guidance to users on laser scanning in archaeology and architecture. English Heritage Publishing.

Bednarik, R.G., 2012. The use of weathering indices in Rock Art Science and Archaeology. Rock Art Research- Volume 29, Number 1, pp. 59-84.

Pipkin, B., Trent, D.D., Hazlett, R, and Bierman, P., 2013, Geology and the Environment, 7th edition, Brookes Cole, Belmont, CA, $624 \mathrm{p}$.

Correia Santos, M. J., Sousa, O., Pires, H., Fonte, J., Gonçalves Seco, L., 2014. Travelling back in Time to Recapture Old Texts: The use of Morphological Residual Model (M.R.M.) for epigraphical reading. Information Technologies for Epigraphy and Cultural Heritage. Studi Humanisti - Serie Antichista, Sapienza Universitá Editricie, pp. 437-454.

Earl, G., Martinez, K., Malzbender, T., 2010. Archaeological applications of polynomial texture mapping: analysis, conservation and representation. Journal of Archaeological Science, 37, (8), 2040-2050

Earl, G., Beale, G. Martinez, K. and Pagi, H., 2010. Polynomial Texture Mapping and Relate Imaging Technologies for the recording, analysis and presentation of archaeological materials. International Archives of Photogrammetry, Remote Sensing and Spatial Information Sciences, UK, Vol. XXXVIII, Part 5.

Gaddi, R., Cusano, M., Bonanni, P., Cacace, C. and Giovagnoli, A., 2015. Monitoring of cultural heritage decay in Rome. Analysis of soiling and erosion phenomena. Engineering Geology for Society and Territory - Volume 8, pp 535-538.

Happa, J., Mudge, M., Debattista, K., Artusi, A., Gonçalves, A. and Chalmers, A., 2009. Illuminating the Past - State of the Art. The 10th International Symposium on Virtual Reality, Archaeology and Cultural Heritage VAST - State of the Art Reports

Keyser, J.m 2001. Rock Varnishing and Weathering in Handbook of Rock Art Research, ed. D.Whitley, Altamira Press, Lanham

Malzbender T., Gelb D. and Wolters H,. 2001. Polynomial Texture Maps. In SIGGRAPH '01: Proceedings of the 28th annual conference on Computer graphics and interactive techniques

Pires, H.,Gonçalves Seco, L., Fonte, J., Correia Santos, M. J., Sousa, O., 2014 Morphological Residual Model: A Tool For Enhancing Epigraphic Readings Of Highly Erosioned Surfaces. Information Technologies for Epigraphy and Cultural Heritage. Studi Humanisti - Serie Antichista, Sapienza Universitá Editricie, pp. 133-144.

Pires, H., Gonçalves-Seco. L., Fonte,, J., Parcero-Oubiña, P. , Fábrega-Álvarez, P., 2015. Morphological Residuals Model - A mesh decimation filtering tool for detection and contrast of archaeological evidences in point-cloud derived models. Journal of Cultural Heritage. Forthcoming.

Pires, H., Bacelar Alves, L., Martinez Rubio, J.,Elorza Arana, A., Gonçalves Seco, L., Fonte, J. 2015. New depictions for ancient carvings. Results of the MRM pilot project at the rock art site Monte Faro, Valença - Portugal. Proceedings of the XVII World Congress of UISPP. Forthcoming.

Plets, G., Verhoeven, G., Cheremisin, D., Plets, R., Bourgeois, J., Stichelbaut, B., Gheyle, W., and De Reu, J., 2012. The deteriorating preservation of the Altai Rock art: assessing threedimensional image-based modelling in rock art research and management. Rock Art Research. 29(2). p.139-156.

Purdya, B.A, Jonesb, K., Mecholskyb, J., Bourneb, G., Hulbert Jr.c, R.C., MacFaddenc, B.J., Churchd, K.L., Warrena, M.W., Jorstade, T.M., Stanfordf, D.J., Wachowiakg, M.J., and Speakman, R.J., 2011. Earliest Art in the Americas: incised image of a proboscidean on a mineralized extinct animal bone from Vero Beach, Florida. Journal of Archaeological Science 38 (11): 2908-2913

Siegesmund, S. , Weiss, S., Vollbretch, A. 2002. Natural Stone, Weathering Phenomena, Conservation Strategies and Case Studies. Geological Society Publishing House. Bath,UK 